\title{
Alterations of Metabolic Genes and Metabolites in Cancer
}

\author{
Eric K. Oermann ${ }^{1,2}$, Jing Wu ${ }^{1,2}$, Kun-Liang Guan ${ }^{3,4}$, and Yue Xiong ${ }^{1,3,5,{ }^{*}}$ \\ ${ }^{1}$ Lineberger Comprehensive Cancer Center, University of North Carolina at Chapel Hill, Chapel \\ Hill, NC 27599, USA \\ ${ }^{2}$ Department of Neurosurgery, University of North Carolina at Chapel Hill, Chapel Hill, NC 27599, \\ USA \\ ${ }^{3}$ Molecular and Cell Biology Lab, Institutes of Biomedical Sciences, Fudan University, Shanghai \\ 200032, China \\ ${ }^{4}$ Department of Pharmacology and Moores Cancer Center, University of California at San Diego, \\ La Jolla, CA 92093-0815, USA. \\ ${ }^{5}$ Department of Biochemistry and Biophysics, University of North Carolina at Chapel Hill, Chapel \\ Hill, NC 27599, USA
}

\section{Abstract}

Altered metabolic regulation has long been observed in human cancer and broadly used in the clinic for tumor detection. Two recent findings-the direct regulation of metabolic enzymes by frequently mutated cancer genes and frequent mutations of several metabolic enzymes themselves in cancer-have renewed interest in cancer metabolism. Supporting a causative role of altered metabolic enzymes in tumorigenesis, abnormal levels of several metabolites have been found to play a direct role in cancer development. The alteration of metabolic genes and metabolites offer not only new biomarkers for diagnosis and prognosis, but also potential new targets for cancer therapy.

\section{Introduction}

Otto Warburg observed more than 80 years ago that tumor cells have altered metabolic regulation; despite having an increased uptake of glucose, tumor cells produce much less ATP than expected from a complete tricarboxylic acid (TCA) cycle coupled to oxidative phosphorylation, and instead accumulate a significant amount of lactate [1-4]. Although the molecular mechanisms and significance of this shift to aerobic glycolysis in tumor cells, commonly known as the Warburg Effect, remain poorly understood, enhanced glucose uptake provides the basis for ${ }^{18}$ FDG-PET technology which has been widely used clinically for tumor detection by injecting patients with a radio-labeled glucose analog, $2\left({ }^{18} \mathrm{~F}\right)-$ fluoro-2-deoxy-D-glucose (FDG), followed by imaging with positron exmission tomography (PET).

\footnotetext{
(C) 2012 Elsevier Ltd. All rights reserved.

*Correspondence: kguan@ucsd.edu, yxiong@email.unc.edu.
}

Publisher's Disclaimer: This is a PDF file of an unedited manuscript that has been accepted for publication. As a service to our customers we are providing this early version of the manuscript. The manuscript will undergo copyediting, typesetting, and review of the resulting proof before it is published in its final citable form. Please note that during the production process errors may be discovered which could affect the content, and all legal disclaimers that apply to the journal pertain. 
Despite its long history and broad clinical relevance, relatively little progress has been made over past four decades in understanding how metabolism is altered in tumor cells and whether this alteration contributes to, or is mere consequence of, tumorigenesis. This is largely due to the fact that cancer research during this period has been focused on genetic mutations in human cancer which, until recently, were not known to target genes encoding for metabolic enzymes. Intensive studies on the PI3K-AKT-PTEN-mTOR tumor suppression pathway, which is frequently altered in many types of cancers, led to the realization that its control of cell growth is achieved in part through sensing and regulating cellular energy metabolism [5-7]. Two lines of evidence-the direct regulation of metabolic genes by known cancer genes and the discovery of mutations of metabolic genes in cancerhave recently been developed that support the theory where, at least in these two cases, altered metabolism contributes to, as opposed to occurs as a consequence of, tumorigenesis. In this review, we will focus on discussing these two lines of scientific inquiry.

\section{Classical cancer genes directly regulate metabolic enzymes}

The levels of a number of metabolic enzymes are altered in different types of human tumors. Yet, in most of these cases, the molecular mechanisms underlying their oncogenic alterations remain to be elucidated. Below, we discuss several cases where changes in the expression of metabolic enzymes or transporters have been linked directly, either genetically or biochemically, to the function of frequently mutated cancer genes (Table 1).

\subsection{Oncogenic activation of KRAS pathway upregulates GLUT1 and glucose uptake}

The classical oncogenes KRAS and BRAF, a pair of effectors in the same signaling pathway which are frequently mutated in a mutually exclusive pattern in a variety of human tumors, have been shown to contribute to the metabolic dysregulation of cancer cells, in part, by stimulating the increased expression of GLUT1, the gene encoding for glucose transporter 1 $[8,9]$. GLUT1 is the ubiquitous mammalian glucose transporter, and it is physiologically increased in the presence of hypoglycemia. In a serial analysis of gene expression (SAGE), GLUT1 was identified as one of three genes that are consistently up-regulated in isogenic colorectal cancer cells with $K R A S$ or $B R A F$ mutations [9]. Supporting a genetic link between oncogenic activation of $K R A S / B R A F$ and upregulation of GLUT1, long-term glucose deprivation of cells with wild-type $K R A S$ and $B R A F$ genes developed constitutive expression of the GLUT1 gene at elevated levels and, notably, a small fraction of them acquired activating mutations in $K R A S$ or $B R A F$ genes [9]. Although the actual mechanism of KRAS/BRAF mediated GLUT1 upregulation remains to be determined, particularly whether it is mediated via an HIF-dependent or -independent process $[9,10]$, the upregulation of GLUT1 increases glucose uptake, a phenomena seen broadly in many types of tumors. Besides its potential role in facilitating tumor initiation, GLUT1 upregulation could also promote the survival of tumor cells in hypoglycemic and hypoxic environments thereby indirectly increasing the proliferative and invasive phenotypes of cancer cells. Supporting this hypothesis, a clinical study recently found a correlation between GLUT1 expression and metastases in patients with advanced cervical cancer, emphasizing the immediate link between cancer cell metabolism and phenotype [11].

\subsection{Myc and HIF activates LDH-A gene expression}

The Myc oncogene encodes a transcription factor and is frequently amplified in many types of human tumors, while HIF-1a, also a transcription factor, is elevated in different types of tumors resulting from loss-of-function mutations targeting its negative regulator, the Von Hippel-Lindau (VHL) tumor suppressor. Both Myc and HIF-1a can bind directly to and activate the expression of lactate dehydrogenase A ( $L D H A)$ [12-14]. HIF-1a accomplishes this through binding a hypoxia response element (HRE) in the $L D H A$ promoter, while Myc 
binds an upstream E-box [13, 14]. LDH is a homo- or heterotetrameric enzyme that is composed of two subunits, A and B, encoded by two distinct genes, $L D H A$ and $L D H B$, resulting in five different isozymes depending on the ratio of the A and B subunits. While the LDH enzyme can catalyze both the forward and backward conversion of pyruvate to lactate, the two subunits have distinct kinetics with LDHA kinetically favoring the forward and LDHB promoting the backward reaction. It has long been known that many tumor types express high levels of LDHA [15]. Clinically, elevated LDH levels have been correlated with poor prognosis and resistance to chemotherapy and radiotherapy. Inhibition of LDHA by either RNA interference or pharmacological agents block tumor progress in vivo [16-18], supporting an important role of elevated LDHA for tumorigenesis and a pathological significance of $L D H A$ gene upregulation by Myc and HIF-1a oncogenes.

\subsection{Myc activates GLS1 gene expression and sustains elevated glutaminolysis}

Renewed interest in the Warburg effect has focused attention in cancer metabolism research on the enzymes and metabolic pathways linked to lactate production, including glutaminolysis, whereby glutamate is catabolized to generate ATP and lactate. A key enzyme involved in glutaminolysis is glutaminase, an amidohydrolase that converts glutamine to glutamate. The human genome contains two glutaminase genes, GLS1 (also known as $G L S$ ) and $G L S 2$, and the expression of both genes have been found to be regulated by two frequently mutated cancer genes, one ( $G L S 1)$ by the Myc oncogene and the other ( $G L S 2)$ by the $\mathrm{p} 53$ tumor suppressor.

The first evidence linking the oncogenic function of Myc to the regulation of glutaminase and cellular glutaminolysis came from the observation that knocking down Myc in a tumor cell line with elevated Myc expression led to significant reduction of glutamine consumption [19]. A search for Myc-regulated mitochondrial proteins subsequently identified $G L S 1$ as a target of Myc [20]. Instead of binding to and activating $G L S 1$ gene expression, Myc indirectly regulates the expression of $G L S 1$ by suppressing two microRNA (miRNA), miR-23a and miR-23b, that target the 3'untranslated region (UTR) of GLS1 gene. A survival benefit for tumor cells is achieved by this Myc-stimulated $G L S 1$ gene expression via increased glutaminolysis leading to the replenishment of TCA cycle intermediates (anaplerosis). Supporting the notion that elevated glutaminase activity is important for the viability of tumor cells was the finding that pharmacological inhibition of a mouse splicing variant of GLS1, Glutaminase C (GAC), inhibits malignant transformation by RhoGTPases and the growth of xenografted tumors [21].

\section{4 p53 activates the expression of GLS2 and TIGAR genes in response to oxidative stresses}

As a transcription factor, p53 regulates the expression of many genes to fulfill its tumor suppressor function in response to various genotoxic stresses such as DNA damage, oncogenic stimulation, nutrient deprivation, and hypoxic conditions. Although most wellcharacterized targets of p53 are involved in either cell cycle regulation or apoptosis, recent studies have identified several metabolic enzymes as the targets of p53 [22]. The first reported metabolic gene as a potential target of p53 was type II hexokinase (HK2), which contains two putative p53 binding elements in its promoter [23]. The functional significance of p53-mediated $H K 2$ activation remains to be elucidated. In a search for novel targets of p53 by microarray, TIGAR (TP53-induced glycolysis and apoptotic regulator), was identified and shown to encode a previously uncharacterized protein with regions homologous to the catalytic domain of fructose 2, 6-bisphosphatase (FBPase2) [24]. The enzyme activity of TIGAR in hydrolyzing fructose-2,6-bisphosphate (F-2,6-BP), a key regulatory metabolite involved in sensing energy status, to fructose-6-phosphate (F6P), was subsequently validated [25]. Induction of TIGAR, like elevated FBPase2, reduces the level 
of F-2,6-BP, which acts as an allosteric activator of phosphofructokinase (PFK). This process results in the inhibition of glycolysis and activation of the pentose phosphatase pathway (PPP) leading to increased levels of glutathione (GSH), a key antioxidant, and the lowering of intracellular reactive oxygen species (ROS).

In addition to TIGAR, glutaminase 2 ( $G L S 2)$, but not $G L S 1$, is another p53 target gene [26, 27]. As well as increasing the production of mitochondrial respiration and ATP production, p53-activated $G L S 2$ expression was also found to elevate the levels of GSH and reduce reactive oxygen species (ROS) in a p53- and GLS2-dependent manner. Knocking down either $p 53$ or compromised this GSH-dependent antioxidant system and lead to ROS accumulation. These findings suggest that p53 may constitute a metabolic checkpoint pathway, in addition to its roles in mediating DNA damage or oncogene checkpoint pathways, by mediating the cellular response to oxidative stress.

It remains a puzzle as to why two GLS enzymes, both localizing in the mitochondria and catalyzing the same reaction, are regulated so differently; one by a proliferation-stimulating oncogene and one by a growth inhibitory tumor suppressor. Several possibilities have been proposed to reconcile this enigma [28], including the difference between two GLS proteins in their kinetics of activation by phosphate and inhibition by product glutamate, or having additional and different properties such as interacting with different proteins. Further studies are needed to determine the different roles and regulation of these two GLS genes in tumorigenesis.

\subsection{Myc promotes alternative splicing of PKM2}

Given the presence of large number of Myc targets in vivo, it is perhaps not surprising to see that Myc regulates yet another metabolic enzyme, PKM2, through the transcriptional activation of its splicing factors. The human genome encodes two distinct pyruvate kinase (PK) genes, PKLR and PKM2, that express four PK isoforms: L, R, M1 and M2 [29]. The L and $\mathrm{R}$ isoforms are expressed specifically in liver and red blood cells, respectively, from the $P K L R$ gene through the use of different promoters [30]. Conversely, M1 and M2 are expressed in most adult tissues and during embryogenesis, respectively, from the PKM2 gene by alternative RNA splicing [31]. Notably, PKM2 is highly expressed in tumors of many different types $[32,33]$. The significance of switching from constitutively active PKM1 to the FBP-regulated PKM2 isoform in tumor cells is not clear at present. Two different roles have been proposed, one focusing on its function in glycolysis in the cytoplasm, and one proposing a glycolysis-independent function in the nucleus. The former view has been proposed for some time, and holds that the switching from constitutive highly active PKM1 to the FBP-regulated, less active PKM2 would decrease the conversion of phosphoenolpyruvate (PEP) to pyruvate which normally enters mitochondria to serve as the precursor for the TCA cycle. As the result of this decreased PK activity, cells would accumulate more glycolytic intermediates, many of which are used for biosynthetic reactions for cell growth and division, including fatty acids, DNA and RNA [34]. The latter role was spurred by a surprising finding that PKM2, but not PKM1, can enter the nucleus where it acts as a transcriptional co-activator with HIF-1a or $\beta$-catenin $[35,36]$, potentially expanding the function of PKM2 beyond glycolysis in the cytoplasm. The mechanism underlying the switch of PKM1-PKM2 alternative splicing remained elusive for a long time, but was recently found to be regulated, in part, by Myc [37]. In this study by David et al., three heterogenous nuclear ribonucleoprotein (hnRNP) proteins, hnRNPA1, hnRNPA2 and hnRNPI (also known as PTB), were found to bind repressively to sequences flanking exon 9 of PK gene, resulting in exon 10 inclusion and the production of PKM 2 mRNA. The expressions of the genes encoding for these three hnRNP are upregulated by Myc, linking the function of Myc oncogene to the altered activity of this major metabolic enzyme [37]. 


\section{Eight metabolic genes encoding for four metabolic enzymes are mutated in human cancer}

The strongest evidence supporting the notion that altered metabolism directly contributes to tumorigenesis comes from the finding that eight genes, $F H, S D H A, S D H B, S D H C, S D H D$, $S D H A F 2, I D H 1$ and $I D H 2$, encoding for the subunits of four different metabolic enzymes, fumarate hydratase $(\mathrm{FH})$, succinate dehydrogenase (SDH), isocitrate dehydrogenase 1 and 2 (IDH1 and IDH2), are mutated, both germinally and somatically, in a number of types of human cancers (Table 2). In addition, although found in only one type of tumor (ovarian carcinoma) and low in prevalence (8 cases out of more than 300), somatic mutations in the L2HGDH gene encoding for L-2-HG dehydrogenase may be pathologically significant in tumorigenesis given the emerging oncogenic activity of its substrate, 2-HG, when accumulated (see below) [38]. We will first review the clinical features of these mutations and then focus the discussion on a newly emerging mechanism that may underline the tumor mutations targeting these four enzymes that are otherwise unrelated in their catalytic properties.

\subsection{Loss of function mutations target all five subunits of SDH in cancer and occur in a mutually exclusive pattern}

The first major metabolic gene found to be mutated in human cancer was the $S D H D$ gene, encoding for a subunit of succinate dehydrogenase (SDH), in familial paraganglioma, a relative benign head and neck tumor [39-41]. SDH is unique in that it is both a TCA cycle enzyme as well as a component of the electron transport chain. It is confined to the inner and outer mitochondrial membranes, and catalyzes the oxidation of succinate to fumarate with the concomitant reduction of ubiquinone to ubiquinol. Like bacterial SDH, human SDH is composed four subunits encoded by four distinct genes, SDHA, SDHB, SDHC and SDHD, and is activated by a newly discovered assembly factor, SDHAF2 (also known as SDH5) [42]. Following the initial finding of $S D H D$ mutations in tumor, both the $S D H B$ and $S D H C$ genes were found to be mutated in renal cell carcinoma and papillary thyroid carcinoma, and reduced expression of $S D H D$ was noted in gastric and colorectal carcinoma [43]. More recently, mutations of both remaining $S D H$ genes, $S D H A F 2$ and $S D H A$, were also identified in familial and sporadic paraganglioma, pheochromocytoma, and gastrointestinal stromal tumors [42, 44-46]. Hence, mutations in all five $S D H$ genes have been linked to tumor development [47]. Thus far, $S D H$ mutations have been reported in more than 650 tumor specimens, and there has been no report for the occurrence of mutations targeting two different SDH subunits in the same tumor. This result indicates that a loss of function mutation in any of the five subunits of the SDH enzyme carries the same functional consequence in contributing to tumorigenesis, likely by causing the reduction or inactivation of the function of SDH holoenzyme in the cell.

\subsection{Loss of function mutations targeting FH gene are found in different type of tumors}

Fumarate hydratase (FH, also known as fumarase) catalyzes the reversible hydration/ dehydration of fumarate to malate. The human genome contains a single $F H$ gene that expresses two forms of fumarase via the use of different translation start sites: a longer form containing a mitochondrial localization signal that participates in the TCA cycle, and a short form localized to the cytoplasm that participates in purine synthesis and the urea cycle. Human FH holoenzyme is very similar to bacterial fumarase C, which functions as a homotetramer with an active site comprised of amino acid residues from three of the four subunits [48]. Mutations targeting the $F H$ gene in tumors were first found in inherited uterine fibroids, skin leiomyomata, and papillary renal cell cancer, [49] and subsequently in leydig cell tumors [50]. Thus far, $\mathrm{FH}$ mutations have been reported in more than 300 tumors. Like $S D H$ mutations, all functionally characterized $F H$ mutations resulted in either a 
complete loss or reduction of FH activity $[50,51]$, indicating a tumor suppressive function of the $\mathrm{FH}$ gene.

\subsection{IDH1 and IDH2 are frequently mutated in human cancer}

A cancer genome project made a surprising discovery in 2008 in the form of recurring mutations in the gene encoding isocitrate dehydrogenase 1 (IDH1) in malignant gliomas [52]. This finding was quickly confirmed by a flurry of studies involving directed sequencing of $I D H 1$ and its homologue $I D H 2$ which cumulatively established that $I D H 1$ and less frequently $\mathrm{IDH} 2$ genes are mutated in more than $75 \%$ of grade $2-3$ gliomas and secondary glioblastomas [53]. A separate cancer genome project comparing the genome from leukemic cells in a patient with acute myeloid leukemia (AML) to the normal skin cells of the same individual also identified a mutation in the IDH1 gene in AML in 2009 [54]. Subsequent direct sequencing in a large number of AML samples established that the IDH1 or IDH 2 genes are mutated in about $20 \%$ of AML [53]. More recently, IDH1 and IDH2 genes were found to be mutated in thyroid carcinomas $(16 \%)[55,56]$, chondrosarcoma (56\%) [57] and enchondroma (85\%) [58, 59]. IDH1 and IDH2 mutations have also been reported in a limited number of samples of several additional types of tumors at lower frequency, including melanoma (4/39) [60], paraganglioma (1/131) [61], prostate cancer (2/75), B-acute lymphoblastic leukemias (B-ALL, 1/60) [62], angioimmunoblastic T-cell lymphoma (AITL, 40\%) [63], and intrahepatic cholangiocarcinoma (23\%) [64]. IDH1 and $\mathrm{IDH} 2$ represent by far the most frequently mutated metabolic genes in human cancer.

\subsection{IDH1 and IDH2 mutations exhibit six unique biochemical and clinical features}

(1) IDH1/2 mutations are all heterozygous and predominantly target a single amino acid substitution, Arg132 in IDH1 or corresponding Arg172 in IDH2, and Arg140 in IDH2, indicating a gain-of-function. (2) $I D H 1$ and $I D H 2$ mutations occur in a mutually exclusive manner, indicating a common underlying biochemical mechanism. (3) IDH1/2 mutations are all somatic, and no germ-line mutation has been reported, consistent with a possible dominant effect of the mutation on cell growth. (4) IDH1/2 mutations occur in a highly restricted tumor spectrum, frequently arising in grade 2-3 gliomas and secondary glioblastomas, but not in primary GBM, in cytogenetically normal AML, but not other subtypes of AML. This feature suggests that the contribution of IDH1/2 mutations to tumorigenesis may be linked to cell fate determination or cell differentiation. (5) IDH1/2 mutations are only found in adult, not in pediatric, glioma or AML patients. (6) IDH1 mutations are associated significantly with better prognosis in glioma patients. The slower growing and less invasiveness of IDH-mutated tumors is consistent with the notion that mutant IDH enzymes, in addition to their tumor-promoting effects, may also cause growth inhibition at the same time. These unique properties of $I D H 1 / 2$ mutation not only raise important mechanistic, biological, and clinical questions about the role of this metabolic pathway in tumorigenesis, but also provide a unique opportunity to develop a strategy for therapeutic intervention based upon the premise of employing small molecular inhibitors against these tumors which may be identifiable in a non-invasive manner using their chemical and clinical characteristics.

\section{Mutations in FH, SDH and IDH genes impair the function of $\alpha-K G$ and inhibit $\alpha-K G-d e p e n d e n t$ dioxygenases}

Several hypotheses have been proposed to explain the mechanism underlying the contribution to tumorigenesis by the mutations targeting the FH, SDH, and IDH enzymes since the first report of $S D H D$ gene mutations in tumors. For traditional cancer genes, experimental increased or decreased expression usually results in detectable changes in cellular phenotype such as increased proliferation, survival, migration, or molecular changes 
associated with one of these cellular features. However, none of these commonly observed hallmarks have been consistently found to associate with the ectopic expression of tumorderived mutants of metabolic genes in cultured cell systems. Given the same subcellular localization of both FH and SDH enzymes (and later IDH2) in mitochondria, and function in the TCA cycle, early attention on the elucidation of biochemical mechanisms underlying the mutations in metabolic genes was focused on mitochondrial dysfunction in cells with SDH and FH mutations [65]. Inactivating mutations in FH and SDH were originally hypothesized to cause mitochondrial dysfunction-induced tumorigenesis by (1) abrogating the mitochondria's ability to trigger apoptosis, (2) generating ROS that damage both cellular and mitochondrial DNA, and (3) stabilizing HIF-1a [66]. The finding that IDH1, the most frequently mutated metabolic gene of the eight, encodes a protein that localizes in the cytoplasm indicates that the effects of metabolic gene mutations on tumorigenesis likely goes beyond direct mitochondrial dysfunction. We will focus the remainder of our discussion in this review on a newly emerging mechanism - impaired activity of a-KGdependent dioxygenases and altered epigenetic control—that may be common to the mutations of all eight metabolic genes.

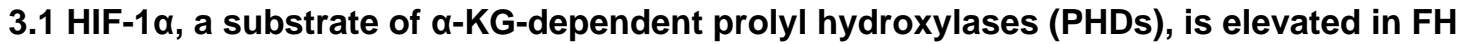 and SDH mutated cells}

a-ketoglutarate $(\mathrm{a}-\mathrm{KG})$-dependent dioxygenases (also known sometimes as oxygen transferases) incorporate both atoms of molecular oxygen into their substrates (Figure 1A). They should not be confused with oxidases, which reduce both oxygen atoms to water, or monooxygenases, which transfer one oxygen atom to the substrate and one to water. $\mathrm{Fe}$ (II)/ a-KG-dependent dioxygenases are present in all living organisms and catalyze hydroxylation reactions on a diverse set of substrates including proteins, alkylated DNA and RNA, lipids, antibiotics, and recently discovered 5-methylcytosine of genomic DNA [6769] (Figure 1B). These enzymes require Fe(II) as a cofactor metal, and utilize a-KG as a cosubstrate to catalyze a reaction in which one oxygen atom from molecular oxygen $\left(\mathrm{O}_{2}\right)$ is attached to a hydroxyl group in the substrate (hydroxylation), while the other is taken up by $\mathrm{a}-\mathrm{KG}$ leading to the decarboxylation of $\mathrm{a}-\mathrm{KG}$ and subsequent release of carbon dioxide $\left(\mathrm{CO}_{2}\right)$ and succinate.

Studies into the mechanism behind how mutations in SDH and FH trigger elevated levels of HIF-1a provided the first evidence that mutations in metabolic enzymes lead to the direct inhibition of a-KG-dependent dioxygenases [70]. It was first described that inhibition or mutation of SDH resulted in an accumulation of its substrate, succinate, which binds directly to and inhibits the activity of PHD, leading to increased stability and elevated levels of both HIF-1a and HIF-2a [71]. Similarly, fumarate, the substrate of FH which is accumulated in $F H$-deficient cells, was also found to inhibit PHD leading to elevated levels of HIF-1a and HIF-2a proteins [72]. Addition of a-KG efficiently relieves the inhibition of PHD by either fumarate or succinate, thereby restoring the hydroxylation of HIF proteins[72]. This finding provided the first evidence that the activity of succinate and fumarate is due to the antagonizing of a-KG dependent processes and negatively regulating a-KG-dependent dioxygenases such as PHDs.

\subsection{IDH1/2 mutants display simultaneous loss and gain of function in the production of $\alpha$ - KG and 2-hydroxyglutarate (2-HG)}

IDH enzymes catalyze the oxidative decarboxylation of isocitrate to produce a-KG. The human proteome contains three distinct IDH enzymes whose activities are dependent on either nicotinamide adenine dinucleotide phosphate ( $\mathrm{NADP}^{+}$-dependent IDH1 and IDH2) or nicotinamide adenine dinucleotide ( $\mathrm{NAD}^{+}$-dependent IDH3). Both IDH2 and IDH3 enzymes are localized in the mitochondria, while IDH1 is localized in the cytoplasm and 
peroxisomes[73]. a-KG plays critical roles in four different metabolic and cellular pathways: (1) as an intermediate in the TCA/Krebs Cycle for energy metabolism, (2) as a precursor of glutamine formation for the amino acid synthesis, (3) as a nitrogen transporter for the urea cycle and detoxification, and (4) as a co-substrate for Fe(II)/a-KG-dependent dioxygenases in oxygen sensing and hydroxylation of various protein and nucleic acid substrates such as histones and DNA. This last function of a-KG has gained very little attention until now, and is emerging as an important regulatory mechanism in the epigenetic control of cellular processes.

The first biochemical change identified in tumor-derived mutant IDH1 and IDH2 was that all mutants of IDH1 and IDH2 lose their catalytic activity in the production of a-KG [74, 75]. This finding led to the examination of the activity of a-KG-dependent PHDs, and the finding that in cultured cells expressing mutant IDH, similarly to cells expressing mutant $\mathrm{FH}$ and SDH, the steady state level of HIF-1a was increased and could be reversed by the treatment of cells with cell-permeable a-KG [74]. This finding supports a rate-limiting role for a-KG in vivo for the a-KG-dependent dioxygenases such as PHDs, and raises the possibility that drugs mimicking a-KG may serve as therapeutic agents for tumors that harbor IDH1 mutations [74].

Subsequently, Dang et al. made a surprising discovery that, in addition to abolishing its normal activity in a-KG production, mutant IDH1 gained a new activity-catalyzing the reduction of a-KG to produce D-2-hydroxyglutarate (D-2-HG, also known as $R-2-\mathrm{HG}$ )[76]. In $I D H 1$ mutated glioma, D-2-HG accumulates to astonishingly high levels of approximately $5-35 \mu \mathrm{mole} / \mathrm{g}$ (or $5-35 \mathrm{mM}$ ). Efforts are currently underway toward the development of magnetic resonance spectroscopy (MRS) to detect non-invasively the accumulation of 2-HG in glioma patients [77]. D-2-HG was also found to accumulate in IDH1- and IDH2-mutated AML [78-80] and enchondroma [58]. A significant level of D-2HG was even detected in the peripheral blood of AML patients carrying a mutation in the IDH1 gene [79]. In fact, ectopic expression of all tumor-derived mutations targeting three hot spots, Arg132 in IDH1, Arg140 and Arg172 in IDH2, have been found to produce and accumulate D-2-HG [81-83]. Accumulation of a different enantiomer, L-2-HG (also known as $S$-2-HG), has previously been linked to L-2-hydroxyglutaric aciduria (L-2HGA), a rare metabolic disorder that is caused by a defect in L-2-HG dehydrogenase (L2HGDH) in mitochondria and is associated with psychomotor retardation, progressive ataxia, leukodystrophy [84, 85], and in a few cases increased risk of developing brain tumors [19]. Neither enantiomer of 2-HG has been found to have any physiological function, and both can be considered as metabolic waste that, if not removed, are toxic or tumorigenic to cells.

\subsection{2-HG is a competitive inhibitor of $\alpha-K G$-dependent dioxygenases that include both histone and DNA demethylases}

In the active site of a-KG-dependent dioxygenases, $a-K G$ uses two oxygen atoms from the a-keto carboxyl end, one from its $\mathrm{C}-1$ carboxylate and one from its $\mathrm{C}-2$ ketone, to coordinate $\mathrm{Fe}(\mathrm{II})$ and two oxygen atoms linked to $\mathrm{C}-5$ at the acetate end to interact with conserved residues in the dioxygenases. 2-HG and $\mathrm{a}-\mathrm{KG}$ are structurally similar, except for the oxidation state at $\mathrm{C}-2$ on which the oxygen in $\mathrm{a}-\mathrm{KG}$ is replaced by a hydroxyl group in 2-HG, suggesting the possibility that 2-HG may bind to these enzymes and function as an antagonist of a-KG. This hypothesis was later confirmed by showing that 2-HG is a competitive inhibitor of multiple a-KG-dependent dioxygenases in vitro, including collagen prolyl hydroxylase (CPHs) involved in collagen processing and endostatin production, PHDs and factor inhibiting-HIF (FIH) involved in HIF-a regulation, several histone lysine demethylases (KDMs), AlkB homologue (ALKBH) involved in DNA repair, $\boldsymbol{\gamma}$-butyrbetaine hydroxylase (BBOX1) involved in carnitine biosynthesis, and DNA hydroxylases in the form of ten-eleven translocases (TETs) [82, 86]. In vivo, ectopic expression of mutant IDH1 
or IDH2 in cultured cells or mutations targeting $I D H 1$ in human gliomas resulted in the decrease of endostatin (the product of CPHs), increase in methylation on multiple histone lysine residues, and inhibition of hydroxylation of 5-methylcytosine (5hmC). More direct evidence supporting an antagonist interaction between a-KG and 2-HG came from the crystal structural analysis of several a-KG-dependent dioxygenases bound with 2-HG which revealed that D-2-HG binds to the active site in close proximity to $\mathrm{Fe}(\mathrm{II})$ and adopts a nearly identical orientation as $\mathrm{a}-\mathrm{KG}$.

2-HG appears to be a rather weak competitive inhibitor of a-KG though. For some a-KGdependent dioxygenases such as C.elegans KDM7A and TET DNA hydroxylases, as much as a 100 fold elevation D-2-HG is needed to achieve more than 50\% inhibition [82].

Comprehensive in vitro assays indicate that the half-maximal inhibitory concentration $\left(\mathrm{IC}_{50}\right)$ varies significantly among different a-KG-dependent dioxygenases, with histone $\mathrm{H} 3 \mathrm{~K} 9$ / H3K36 dual specificity demethylases KDM4A/JMJD2A and KDM4C/JMJD2C being the most sensitive ( $\mathrm{IC}_{50}=24 \mu \mathrm{M}$ and $79 \mu \mathrm{M}$, respectively), and PHD2 and BBOX being very resistant ( $\mathrm{IC}_{50}=13 \mathrm{mM}$ and $4 \mathrm{mM}$, respectively) [86]. Consistent for all enzymes that have been examined, L-2-HG appears to be 3 to 15 times more potent than D-2-HG. Both the significance and the mechanism of this higher potency are not clear at present. L-2-HG has not been found to be associated with tumor development, and has been suggested to exhibit possibly a kinetics that are different from D-2-HG [86].

\subsection{Genetic evidence supports TET DNA hydroxylases as a pathologic target of 2-HG}

Of the more than 60 estimated a-KG-dependent dioxygenases in mammalian cells [87], TET proteins are the newest members $[69,88]$. TET proteins catalyze a three-step iterative oxidation reaction: converting $5 \mathrm{mC}$ to first to $5 \mathrm{hmC}$, then $5 \mathrm{hmC}$ to 5 -formylcytosine $(5 \mathrm{fC})$, and finally $5 \mathrm{fC}$ to 5-carboxylcytosine (5caC) [88-91]. A subsequent decarboxylation of $5 \mathrm{caC}$, by either a thymine-DNA glycosylase or other DNA repair enzyme, could then lead to DNA demethylation. Inhibition of the TET family of DNA hydroxylases was demonstrated both in vivo, in cells expressing mutant IDH1 or IDH2, and in vitro [81] [82]. Importantly, there are two lines of genetic evidence that supports TET DNA hydroxylases as being pathologically relevant targets of $I D H 1$ mutations. First, promoter DNA methylation profiling analysis has revealed that a subset of glioblastoma, known as the proneural subgroup [92], are enriched for $I D H 1$ mutations and display hypermethylation at a large number of loci [93], suggesting a potential link between IDH1 mutation and increased DNA methylation which could be explained by the 2-HG inhibition of TET activity. Second, inactivating mutations of the TET2 gene were found in about $22 \%$ of AML cases [94, 95], notably occurring in a mutually exclusive manner with that of $I D H 1 / 2$ genes in AML [81]. Genetic evidence supporting the pathological relevance of other a-KG-dependent dioxygenases to tumorigenesis driven by $I D H 1 / 2$ mutations has not been reported at present.

A critical issue related to the significance of the IDH-TET regulation in tumor suppression is the identification of specific targets whose expression is affected by $I D H$ mutation induced hypermethylation and which contribute to gliomagenesis are yet to be identified. Searching for genes which are differentially methylated between tumors with mutated verse wild-type IDH1/2 genes in both glioma and AML have yielded many potential candidates of IDH targets $[81,92,93,96]$, but no clear pathway has emerged. An alternative model to this IDH mutation-TET inhibition-promoter methylation-targeted gene axis is that broad and random alterations in genomic methylation landscape create an epigenetic milieu which confers a selective advantage to $I D H$ mutant clones that facilitates oncogenesis. This may represent a phenomenon of "epigenomic instability", similar to the known "genomic instability" that is associated with mutations targeting DAN repair pathway. 
3.5 Could fumarate and succinate also function as $\alpha-K G$ antagonists to negatively regulate other $\alpha-K G-d e p e n d e n t$ dioxygenases besides PHDs?

Structurally, both succinate and fumarate are also similar to a-KG and 2-HG. They have the same acetate end and include two oxygen atoms linked to C-5 that are used by a-KG and 2HG to interact with conserved residues in the dioxygenases. Such structural similarity suggests that, in addition to PHDs, both fumarate and succinate in $F H$ and $S D H$ deficient tumor cells may negatively regulate additional a-KG-dependent dioxygenases either by competitive inhibition like 2-HG. Supporting this idea, yeast cells deficient for SDH ( sdh2 2 ) accumulated succinate and had increased dimethylated H3K36. In vitro, succinate was found to inhibit human H3K9 histone demethylase KDM4D/JMJD2D with an estimated 10 to 100 folds higher potency than required to compete with a-KG [97]. Further studies are needed to extend this finding and to determine whether fumarate also compete with a-KG and interferes with a-KG-dependent dioxygenases.

The similar structure and chemical properties of these three oncometabolites, 2-HG, succinate, fumarate, combined with evidence that all three can antagonize $a-K G$ raises the interesting implication that the combined concentration of these three oncometabolites, as opposed to the individual concentrations, may be the more relevant concentration to the regulation of $\mathrm{a}-\mathrm{KG}$ dependent dioxygenases and epigenetic stability in the cell. Considering succinate is the product of a-KG-dependent dioxygenases, an alternative model would be that the high levels of succinate accumulated in FH or SDH mutated cells inhibit the activity of a-KG-dependent dioxygenases through product inhibition.

\subsection{Accumulation of fumarate in FH-deficient cells causes aberrant succination of many proteins, including antioxidant regulator, KEAP1}

Very recently, a new function of fumarate — covalently attaching to cysteine residues-was reported that is independent of its regulation of a-KG-dependent dioxygenases and is significantly upregulated in $F H$-deficient cells $[98,99]$. Fumarate can react spontaneously with cysteine sulphydryl groups by a Michael reaction (nucleophilic addition of a carbanion to an a, $\beta$-unsaturated carbonyl compound) to form a stable chemical modification of protein, $S$-(2-succinyl) cysteine (2SC) with this reaction being named, a bit inconveniently for this discussion, as succination [100]. Prompted by this finding and the accumulation of fumarate in $F H$-deficient cells, Pollard and his colleagues examined the levels of succinated proteins in both Fh1-deficient mouse embryonic fibroblasts (MEFs), and in an $F H$-deficient HLRCC tumor cell line using antibodies recognizing 2SC [99]. Significantly higher levels of 2SC-modified proteins were found in both cell lines, but not in normal tissues or tumors not associated with $\mathrm{FH}$ mutation. A large number of proteins are apparently succinated in $\mathrm{FH}$ deficient cells, making the aberrant succination a robust biomarker for the detection of $\mathrm{FH}$ deficient tissues. One target of fumarate modification, Kelch-like ECH-associated protein 1 (KEAP1), was identified and functionally characterized in a subsequent study $[98,101]$. Two separate gene expression profiling studies between $F H$ wild-type and deficient cells identified the antioxidant pathway mediated by the nuclear factor (erythroid-derived 2)-like 2 (Nrf2) being one of the most significantly activated pathways in Fh1 null cells. The principal regulator of NRF2 is KEAP1 which binds to and targets NRF2 for ubiquitylation and degradation, and multiple cysteine residues in KEAP1 are critical for KEAP1 to interact with NRF2. KEAP1 was found to be succinated at multiple cysteine residues in Fh1deficient, but not wild-type MEFs, and conversely repressed several NRF2 targets in wildtype, but not Fh1-deficient cells. Feeding cells with cell-permeable fumarate increased the expression of NRF2 proteins. These findings suggest that the aberrant modification of cellular proteins by abnormally accumulated fumarate in $\mathrm{FH}$-deficient cells can alter specific cellular pathways, such as the NRF2-mediated oxidative stress response, and provide an 
example of a potentially pathological post-translational modification directly mediated by an oncometabolite.

\section{Conclusion}

Over the past decade, we have seen a resurgence of interest in the study of tumor metabolism inspired in part by the discovery of the direct regulation of metabolic enzymes by frequently mutated classical cancer genes, and more immediately by the discovery of tumor mutations targeting human metabolic enzymes. One unique aspect that differentiates metabolic regulation from other cellular regulatory pathways which commonly involve regulation at the level of gene expression and protein function, is that levels of metabolites are not merely the product of metabolic enzyme activity, but can also play regulatory roles to other enzymes. The study of three putative oncometabolites as discussed above (2-HG, succinate, and fumarate) has taught us that the reach of these metabolites in the regulation of cell activity can extend beyond metabolic enzymes to a potentially large number of a-KG dependent dioxygenases which control diverse cellular processes from transcription to posttranslational modification. Like classical oncogenes, two of these three metabolites, succinate and fumarate, perform important physiological function for normal cell metabolism and only became oncogenic when their amount accumulated to abnormally high levels. Rapid progress is being made in the development of mass spectrometry based technology for the rapid detection and accurate quantification of metabolites in the field of metabolomics. The discovery of 2-HG production by mutant IDH provides an excellent example to illustrate the promise of this new technology. We can anticipate these technological developments will significantly facilitate attempts to determine how the levels of metabolites are changed both in physiologic stress responses, such as nutrient deprivation and oxidative stress, as well as during tumor development.

The second unique aspect emerging from the study of mutant metabolic genes is that changes in the levels of metabolites may link changes in extracellular conditions, the socalled microenvironment, to gene expression. Such a principle has long been established in bacterial metabolic regulation, but is only beginning to emerge in higher eukaryotic and human cells. The finding that three oncometabolites can affect DNA and histone methylation suggests that altered metabolites, besides acute and short-term responses to the changes of nutrient conditions, may impact epigenetic control and cell fate determination and differentiation. It is notable that direct genetic evidence for these three putative oncometabolites is lacking, with most evidence supporting their pathophysiological role being derived from cellular and biochemical studies thus far.

While the cellular signals leading to the regulation of metabolic genes by classical cancer genes are relatively clear from decades of investigation into these cancer genes, it is less clear what signals or stressors, besides mutation, would affect the intracellular levels of oncometabolites. This concern is of immediate relevance to the feasibility of targeting metabolic enzymes for cancer therapy. For example, could $I D H$ mutant tumors remain addicted to high levels of 2-HG and therefore be susceptible to inhibition of the 2-HG producing mutation of IDH? If, like 2-HG, both fumarate and succinate are indeed contributing to tumorigenesis by antagonizing $\mathrm{a}-\mathrm{KG}$, could $\mathrm{a}-\mathrm{KG}$ itself be exploited as a therapeutic agent for tumors with a mutation in the $I D H, F H$, or $S D H$ genes? The study of these oncometabolites offers the opportunity not only to understand how altered metabolism contributes to tumorigenesis, but also to uncover the elusive link between cancer and other metabolic diseases such as diabetes and obesity. 


\section{Highlights}

- Classical cancer genes directly regulate metabolic enzymes.

- Genes encoding eight genes of four metabolic enzymes are mutated in cancer.

- Three oncometabolites inhibit a-KG dependent dioxygenases.

- Oncometabolites may link cancer genetics, epigenetics, and microenvironment.

\section{Acknowledgments}

J.W. is supported by a National Cancer Institute NIH K-12 career development grant to the University of North Carolina at Chapel Hill. E.K.O. is supported by a Doris Duke Charitable Foundation Clinical Research Fellowship. This study is supported by NIH grants to K.L.G and Y.X.

\section{References}

1. Warburg O. On respiratory impairment in cancer cells. Science. 1956; 124:269-270. [PubMed: 13351639]

2. Warburg O. On the origin of cancer cells. Science. 1956; 123:309-314. [PubMed: 13298683]

3. Hsu PP, Sabatini DM. Cancer cell metabolism: Warburg and beyond. Cell. 2008; 134:703-707. [PubMed: 18775299]

4. Vander Heiden MG, Cantley LC, Thompson CB. Understanding the Warburg effect: the metabolic requirements of cell proliferation. Science. 2009; 324:1029-1033. [PubMed: 19460998]

5. DeBerardinis RJ, Lum JJ, Hatzivassiliou G, Thompson CB. The biology of cancer: metabolic reprogramming fuels cell growth and proliferation. Cell metabolism. 2008; 7:11-20. [PubMed: 18177721]

6. Manning BD, Cantley LC. AKT/PKB signaling: navigating downstream. Cell. 2007; 129:12611274. [PubMed: 17604717]

7. Zoncu R, Efeyan A, Sabatini DM. mTOR: from growth signal integration to cancer, diabetes and ageing. Nature reviews Molecular cell biology. 2011; 12:21-35.

8. Flier JS, Mueckler MM, Usher P, Lodish HF. Elevated levels of glucose transport and transporter messenger RNA are induced by ras or src oncogenes. Science. 1987; 235:1492-1495. [PubMed: 3103217]

9. Yun J, Rago C, Cheong I, Pagliarini R, Angenendt P, Rajagopalan H, et al. Glucose deprivation contributes to the development of KRAS pathway mutations in tumor cells. Science. 2009; 325:1555-1559. [PubMed: 19661383]

10. Chen C, Pore N, Behrooz A, Ismail-Beigi F, Maity A. Regulation of glut1 mRNA by hypoxiainducible factor-1. Interaction between H-ras and hypoxia. The Journal of biological chemistry. 2001; 276:9519-9525. [PubMed: 11120745]

11. Airley R, Loncaster J, Davidson S, Bromley M, Roberts S, Patterson A, et al. Glucose transporter glut-1 expression correlates with tumor hypoxia and predicts metastasis-free survival in advanced carcinoma of the cervix. Clinical cancer research : an official journal of the American Association for Cancer Research. 2001; 7:928-934. [PubMed: 11309343]

12. Lewis BC, Shim H, Li Q, Wu CS, Lee LA, Maity A, et al. Identification of putative c-Mycresponsive genes: characterization of, rcl, a novel growth-related gene. Molecular and cellular biology. 1997; 17:4967-4978. [PubMed: 9271375]

13. Shim H, Dolde C, Lewis BC, Wu CS, Dang G, Jungmann RA, et al. c-Myc transactivation of LDHA: implications for tumor metabolism and growth. Proc Natl Acad Sci U S A. 1997; 94:6658-6663. [PubMed: 9192621]

14. Semenza GL, Jiang BH, Leung SW, Passantino R, Concordet JP, Maire P, et al. Hypoxia response elements in the aldolase A, enolase 1, and lactate dehydrogenase A gene promoters contain essential binding sites for hypoxia-inducible factor 1. The Journal of biological chemistry. 1996; 271:32529-32537. [PubMed: 8955077] 
15. Goldman RD, Kaplan NO, Hall TC. Lactic Dehydrogenase in Human Neoplastic Tissues. Cancer research. 1964; 24:389-399. [PubMed: 14147812]

16. Fantin VR, St-Pierre J, Leder P. Attenuation of LDH-A expression uncovers a link between glycolysis, mitochondrial physiology, and tumor maintenance. Cancer Cell. 2006; 9:425-434. [PubMed: 16766262]

17. Le A, Cooper CR, Gouw AM, Dinavahi R, Maitra A, Deck LM, et al. Inhibition of lactate dehydrogenase A induces oxidative stress and inhibits tumor progression. Proceedings of the National Academy of Sciences of the United States of America. 2010; 107:2037-2042. [PubMed: 20133848]

18. Xie H, Valera VA, Merino MJ, Amato AM, Signoretti S, Linehan WM, et al. LDH-A inhibition, a therapeutic strategy for treatment of hereditary leiomyomatosis and renal cell cancer. Mol Cancer Ther. 2009; 8:626-635. [PubMed: 19276158]

19. Aghili M, Zahedi F, Rafiee E. Hydroxyglutaric aciduria and malignant brain tumor: a case report and literature review. J Neurooncol. 2009; 91:233-236. [PubMed: 18931888]

20. Gao P, Tchernyshyov I, Chang TC, Lee YS, Kita K, Ochi T, et al. c-Myc suppression of miR-23a/b enhances mitochondrial glutaminase expression and glutamine metabolism. Nature. 2009; 458:762-765. [PubMed: 19219026]

21. Wang JB, Erickson JW, Fuji R, Ramachandran S, Gao P, Dinavahi R, et al. Targeting mitochondrial glutaminase activity inhibits oncogenic transformation. Cancer cell. 2010; 18:207219. [PubMed: 20832749]

22. Vousden KH, Prives C. Blinded by the Light: The Growing Complexity of p53. Cell. 2009; 137:413-431. [PubMed: 19410540]

23. Mathupala SP, Heese C, Pedersen PL. Glucose catabolism in cancer cells. The type II hexokinase promoter contains functionally active response elements for the tumor suppressor p53. The Journal of biological chemistry. 1997; 272:22776-22780. [PubMed: 9278438]

24. Bensaad K, Tsuruta A, Selak MA, Vidal MN, Nakano K, Bartrons R, et al. TIGAR, a p53inducible regulator of glycolysis and apoptosis. Cell. 2006; 126:107-120. [PubMed: 16839880]

25. Li H, Jogl G. Structural and biochemical studies of TIGAR (TP53-induced glycolysis and apoptosis regulator). The Journal of biological chemistry. 2009; 284:1748-1754. [PubMed: 19015259]

26. Suzuki S, Tanaka T, Poyurovsky MV, Nagano H, Mayama T, Ohkubo S, et al. Phosphate-activated glutaminase (GLS2), a p53-inducible regulator of glutamine metabolism and reactive oxygen species. Proceedings of the National Academy of Sciences of the United States of America. 2010; 107:7461-7466. [PubMed: 20351271]

27. Lu W, Pelicano H, Huang P. Cancer metabolism: is glutamine sweeter than glucose? Cancer Cell. 2010; 18:199-200. [PubMed: 20832746]

28. Hu W, Zhang C, Wu R, Sun Y, Levine A, Feng Z. Glutaminase 2, a novel p53 target gene regulating energy metabolism and antioxidant function. Proceedings of the National Academy of Sciences of the United States of America. 2010; 107:7455-7460. [PubMed: 20378837]

29. Mazurek S. Pyruvate kinase type M2: A key regulator of the metabolic budget system in tumor cells. The international journal of biochemistry \& cell biology. 2010

30. Noguchi T, Yamada K, Inoue H, Matsuda T, Tanaka T. The L- and R-type isozymes of rat pyruvate kinase are produced from a single gene by use of different promoters. The Journal of biological chemistry. 1987; 262:14366-14371. [PubMed: 3654663]

31. Noguchi T, Inoue H, Tanaka T. The M1- and M2-type isozymes of rat pyruvate kinase are produced from the same gene by alternative RNA splicing. The Journal of biological chemistry. 1986; 261:13807-13812. [PubMed: 3020052]

32. Yamada K, Noguchi T. Alteration of isozyme gene expression during cell differentiation and oncogenesis. Nippon Rinsho. 1995; 53:1112-1118. [PubMed: 7602764]

33. Mazurek S, Boschek CB, Hugo F, Eigenbrodt E. Pyruvate kinase type M2 and its role in tumor growth and spreading. Semin Cancer Biol. 2005; 15:300-308. [PubMed: 15908230]

34. Wellen KE, Thompson CB. Cellular metabolic stress: considering how cells respond to nutrient excess. Molecular cell. 2010; 40:323-332. [PubMed: 20965425] 
35. Luo W, Hu H, Chang R, Zhong J, Knabel M, O'Meally R, et al. Pyruvate kinase M2 is a PHD3stimulated coactivator for hypoxia-inducible factor 1. Cell. 2011; 145:732-744. [PubMed: 21620138]

36. Yang W, Xia Y, Ji H, Zheng Y, Liang J, Huang W, et al. Nuclear PKM2 regulates beta-catenin transactivation upon EGFR activation. Nature. 2011

37. David CJ, Chen M, Assanah M, Canoll P, Manley JL. HnRNP proteins controlled by c-Myc deregulate pyruvate kinase mRNA splicing in cancer. Nature. 2010; 463:364-368. [PubMed: 20010808]

38. Integrated genomic analyses of ovarian carcinoma. Nature. 2011; 474:609-615. [PubMed: 21720365]

39. Baysal BE, Ferrell RE, Willett-Brozick JE, Lawrence EC, Myssiorek D, Bosch A, et al. Mutations in SDHD, a mitochondrial complex II gene, in hereditary paraganglioma. Science. 2000; $287: 848-$ 851. [PubMed: 10657297]

40. Niemann S, Muller U. Mutations in SDHC cause autosomal dominant paraganglioma, type 3. Nature genetics. 2000; 26:268-270. [PubMed: 11062460]

41. Astuti D, Douglas F, Lennard TW, Aligianis IA, Woodward ER, Evans DG, et al. Germline SDHD mutation in familial phaeochromocytoma. Lancet. 2001; 357:1181-1182. [PubMed: 11323050]

42. Hao HX, Khalimonchuk O, Schraders M, Dephoure N, Bayley JP, Kunst H, et al. SDH5, a gene required for flavination of succinate dehydrogenase, is mutated in paraganglioma. Science. 2009; 325:1139-1142. [PubMed: 19628817]

43. Bayley JP, Devilee P, Taschner PE. The SDH mutation database: an online resource for succinate dehydrogenase sequence variants involved in pheochromocytoma, paraganglioma and mitochondrial complex II deficiency. BMC Med Genet. 2005; 6:39. [PubMed: 16288654]

44. Burnichon N, Briere JJ, Libe R, Vescovo L, Riviere J, Tissier F, et al. SDHA is a tumor suppressor gene causing paraganglioma. Human molecular genetics. 2010; 19:3011-3020. [PubMed: 20484225]

45. Pantaleo MA, Astolfi A, Indio V, Moore R, Thiessen N, Heinrich MC, et al. SDHA loss-offunction mutations in KIT-PDGFRA wild-type gastrointestinal stromal tumors identified by massively parallel sequencing. Journal of the National Cancer Institute. 2011; 103:983-987. [PubMed: 21505157]

46. Korpershoek E, Favier J, Gaal J, Burnichon N, van Gessel B, Oudijk L, et al. SDHA Immunohistochemistry Detects Germline SDHA Gene Mutations in Apparently Sporadic Paragangliomas and Pheochromocytomas. The Journal of clinical endocrinology and metabolism. 2011; 96:E1472-E1476. [PubMed: 21752896]

47. Bardella C, Pollard PJ, Tomlinson I. SDH mutations in cancer. Biochimica et biophysica acta. 2011; 1807:1432-1443. [PubMed: 21771581]

48. Weaver TM, Levitt DG, Donnelly MI, Stevens PP, Banaszak LJ. The multisubunit active site of fumarase C from Escherichia coli. Nature structural biology. 1995; 2:654-662.

49. Tomlinson IP, Alam NA, Rowan AJ, Barclay E, Jaeger EE, Kelsell D, et al. Germline mutations in FH predispose to dominantly inherited uterine fibroids, skin leiomyomata and papillary renal cell cancer. Nature genetics. 2002; 30:406-410. [PubMed: 11865300]

50. Bayley JP, Launonen V, Tomlinson IP. The FH mutation database: an online database of fumarate hydratase mutations involved in the MCUL (HLRCC) tumor syndrome and congenital fumarase deficiency. BMC Med Genet. 2008; 9:20. [PubMed: 18366737]

51. Alam NA, Olpin S, Rowan A, Kelsell D, Leigh IM, Tomlinson IP, et al. Missense mutations in fumarate hydratase in multiple cutaneous and uterine leiomyomatosis and renal cell cancer. J Mol Diagn. 2005; 7:437-443. [PubMed: 16237213]

52. Parsons DW, Jones S, Zhang X, Lin JC, Leary RJ, Angenendt P, et al. An integrated genomic analysis of human glioblastoma multiforme. Science. 2008; 321:1807-1812. [PubMed: 18772396]

53. Dang L, Jin S, Su SM. IDH mutations in glioma and acute myeloid leukemia. Trends in molecular medicine. 2010; 16:387-397. [PubMed: 20692206]

54. Mardis ER, Ding L, Dooling DJ, Larson DE, McLellan MD, Chen K, et al. Recurring mutations found by sequencing an acute myeloid leukemia genome. N Engl J Med. 2009; 361:1058-1066. [PubMed: 19657110] 
55. Hemerly JP, Bastos AU, Cerutti JM. Identification of several novel non-p.R132 IDH1 variants in thyroid carcinomas. Eur J Endocrinol. 2010; 163:747-755. [PubMed: 20702649]

56. Murugan AK, Bojdani E, Xing M. Identification and functional characterization of isocitrate dehydrogenase 1 (IDH1) mutations in thyroid cancer. Biochemical and biophysical research communications. 2010; 393:555-559. [PubMed: 20171178]

57. Amary MF, Bacsi K, Maggiani F, Damato S, Halai D, Berisha F, et al. IDH1 and IDH2 mutations are frequent events in central chondrosarcoma and central and periosteal chondromas but not in other mesenchymal tumours. The Journal of pathology. 2011; 224:334-343. [PubMed: 21598255]

58. Amary MF, Damato S, Halai D, Eskandarpour M, Berisha F, Bonar F, et al. Ollier disease and Maffucci syndrome are caused by somatic mosaic mutations of IDH1 and IDH2. Nat Genet. 2011

59. Pansuriya TC, van Eijk R, d'Adamo P, van Ruler MA, Kuijjer ML, Oosting J, et al. Somatic mosaic IDH1 and IDH2 mutations are associated with enchondroma and spindle cell hemangioma in Ollier disease and Maffucci syndrome. Nat Genet. 2011

60. Shibata T, Kokubu A, Miyamoto M, Sasajima Y, Yamazaki N. Mutant IDH1 confers an in vivo growth in a melanoma cell line with BRAF mutation. The American journal of pathology. 2011; 178:1395-1402. [PubMed: 21356389]

61. Gaal J, Burnichon N, Korpershoek E, Roncelin I, Bertherat J, Plouin PF, et al. Isocitrate dehydrogenase mutations are rare in pheochromocytomas and paragangliomas. J Clin Endocrinol Metab. 2010; 95:1274-1278. [PubMed: 19915015]

62. Kang MR, Kim MS, Oh JE, Kim YR, Song SY, Seo SI, et al. Mutational analysis of IDH1 codon 132 in glioblastomas and other common cancers. Int J Cancer. 2009; 125:353-355. [PubMed: 19378339]

63. Cairns RA, Iqbal J, Lemonnier F, Kucuk C, de Leval L, Jais JP, et al. IDH2 mutations are frequent in angioimmunoblastic T-cell lymphoma. Blood. 2012

64. Borger DR, Tanabe KK, Fan KC, Lopez HU, Fantin VR, Straley KS, et al. Frequent Mutation of Isocitrate Dehydrogenase (IDH) 1 and IDH2 in Cholangiocarcinoma Identified Through BroadBased Tumor Genotyping. The oncologist. 2011

65. Eng C, Kiuru M, Fernandez MJ, Aaltonen LA. A role for mitochondrial enzymes in inherited neoplasia and beyond. Nature reviews Cancer. 2003; 3:193-202.

66. Gottlieb E, Tomlinson IP. Mitochondrial tumour suppressors: a genetic and biochemical update. Nature reviews Cancer. 2005; 5:857-866.

67. Hausinger RP. FeII/alpha-ketoglutarate-dependent hydroxylases and related enzymes. Crit Rev Biochem Mol Biol. 2004; 39:21-68. [PubMed: 15121720]

68. Loenarz C, Schofield CJ. Expanding chemical biology of 2-oxoglutarate oxygenases. Nature chemical biology. 2008; 4:152-156.

69. Iyer LM, Tahiliani M, Rao A, Aravind L. Prediction of novel families of enzymes involved in oxidative and other complex modifications of bases in nucleic acids. Cell Cycle. 2009; 8:16981710. [PubMed: 19411852]

70. Pollard PJ, Briere JJ, Alam NA, Barwell J, Barclay E, Wortham NC, et al. Accumulation of Krebs cycle intermediates and over-expression of HIF1alpha in tumours which result from germline FH and SDH mutations. Human molecular genetics. 2005; 14:2231-2239. [PubMed: 15987702]

71. Selak MA, Armour SM, MacKenzie ED, Boulahbel H, Watson DG, Mansfield KD, et al. Succinate links TCA cycle dysfunction to oncogenesis by inhibiting HIF-alpha prolyl hydroxylase. Cancer cell. 2005; 7:77-85. [PubMed: 15652751]

72. Isaacs JS, Jung YJ, Mole DR, Lee S, Torres-Cabala C, Chung YL, et al. HIF overexpression correlates with biallelic loss of fumarate hydratase in renal cancer: novel role of fumarate in regulation of HIF stability. Cancer cell. 2005; 8:143-153. [PubMed: 16098467]

73. Winkler BS, DeSantis N, Solomon F. Multiple NADPH-producing pathways control glutathione (GSH) content in retina. Experimental Eye Research. 1986; 43:829-847. [PubMed: 3803464]

74. Zhao S, Lin Y, Xu W, Jiang W, Zha Z, Wang P, et al. Glioma-derived mutations in IDH1 dominantly inhibit IDH1 catalytic activity and induce HIF-1alpha. Science. 2009; 324:261-265. [PubMed: 19359588]

75. Yan H, Parsons DW, Jin G, McLendon R, Rasheed BA, Yuan W, et al. IDH1 and IDH2 mutations in gliomas. N Engl J Med. 2009; 360:765-773. [PubMed: 19228619] 
76. Dang L, White DW, Gross S, Bennett BD, Bittinger MA, Driggers EM, et al. Cancer-associated IDH1 mutations produce 2-hydroxyglutarate. Nature. 2009; 462:739-744. [PubMed: 19935646]

77. Pope WB, Prins RM, Albert Thomas M, Nagarajan R, Yen KE, Bittinger MA, et al. Non-invasive detection of 2-hydroxyglutarate and other metabolites in IDH1 mutant glioma patients using magnetic resonance spectroscopy. J Neurooncol. 2011

78. Ward PS, Patel J, Wise DR, Abdel-Wahab O, Bennett BD, Coller HA, et al. The common feature of leukemia-associated IDH1 and IDH2 mutations is a neomorphic enzyme activity converting alpha-ketoglutarate to 2-hydroxyglutarate. Cancer Cell. 2010; 17:225-234. [PubMed: 20171147]

79. Gross S, Cairns RA, Minden MD, Driggers EM, Bittinger MA, Jang HG, et al. Cancer-associated metabolite 2-hydroxyglutarate accumulates in acute myelogenous leukemia with isocitrate dehydrogenase 1 and 2 mutations. J Exp Med. 2010; 207:339-344. [PubMed: 20142433]

80. Andersson AK, Miller DW, Lynch JA, Lemoff AS, Cai Z, Pounds SB, et al. IDH1 and IDH2 mutations in pediatric acute leukemia. Leukemia. 2011; 25:1570-1577. [PubMed: 21647154]

81. Figueroa ME, Abdel-Wahab O, Lu C, Ward PS, Patel J, Shih A, et al. Leukemic IDH1 and IDH2 mutations result in a hypermethylation phenotype, disrupt TET2 function, and impair hematopoietic differentiation. Cancer Cell. 2010; 18:553-567. [PubMed: 21130701]

82. Xu W, Yang H, Liu Y, Yang Y, Wang P, Kim SH, et al. Oncometabolite 2-hydroxyglutarate is a competitive inhibitor of alpha-ketoglutarate-dependent dioxygenases. Cancer Cell. 2011; 19:1730. [PubMed: 21251613]

83. Ward PS, Cross JR, Lu C, Weigert O, Abel-Wahab O, Levine RL, et al. Identification of additional IDH mutations associated with oncometabolite R(-)-2-hydroxyglutarate production. Oncogene. 2011

84. Rzem R, Veiga-da-Cunha M, Noel G, Goffette S, Nassogne MC, Tabarki B, et al. A gene encoding a putative $\mathrm{FAD}$-dependent L-2-hydroxyglutarate dehydrogenase is mutated in L-2-hydroxyglutaric aciduria. Proc Natl Acad Sci U S A. 2004; 101:16849-16854. [PubMed: 15548604]

85. Topcu M, Jobard F, Halliez S, Coskun T, Yalcinkayal C, Gerceker FO, et al. L-2-Hydroxyglutaric aciduria: identification of a mutant gene C14orf160, localized on chromosome 14q22.1. Human molecular genetics. 2004; 13:2803-2811. [PubMed: 15385440]

86. Chowdhury R, Yeoh KK, Tian YM, Hillringhaus L, Bagg EA, Rose NR, et al. The oncometabolite 2-hydroxyglutarate inhibits histone lysine demethylases. EMBO Rep. 2011; 12:463-469. [PubMed: 21460794]

87. Rose NR, McDonough MA, King ON, Kawamura A, Schofield CJ. Inhibition of 2-oxoglutarate dependent oxygenases. Chem Soc Rev. 2011; 40:4364-4397. [PubMed: 21390379]

88. Tahiliani M, Koh KP, Shen Y, Pastor WA, Bandukwala H, Brudno Y, et al. Conversion of 5methylcytosine to 5-hydroxymethylcytosine in mammalian DNA by MLL partner TET1. Science. 2009; 324:930-935. [PubMed: 19372391]

89. Ito S, D'Alessio AC, Taranova OV, Hong K, Sowers LC, Zhang Y. Role of Tet proteins in $5 \mathrm{mC}$ to 5hmC conversion, ES-cell self-renewal and inner cell mass specification. Nature. 2010; 466:11291133. [PubMed: 20639862]

90. He YF, Li BZ, Li Z, Liu P, Wang Y, Tang Q, et al. Tet-mediated formation of 5-carboxylcytosine and its excision by TDG in mammalian DNA. Science. 2011; 333:1303-1307. [PubMed: 21817016]

91. Ito S, Shen L, Dai Q, Wu SC, Collins LB, Swenberg JA, et al. Tet proteins can convert 5methylcytosine to 5-formylcytosine and 5-carboxylcytosine. Science. 2011; 333:1300-1303. [PubMed: 21778364]

92. Verhaak RG, Hoadley KA, Purdom E, Wang V, Qi Y, Wilkerson MD, et al. Integrated genomic analysis identifies clinically relevant subtypes of glioblastoma characterized by abnormalities in PDGFRA, IDH1, EGFR, and NF1. Cancer Cell. 2010; 17:98-110. [PubMed: 20129251]

93. Noushmehr H, Weisenberger DJ, Diefes K, Phillips HS, Pujara K, Berman BP, et al. Identification of a $\mathrm{CpG}$ island methylator phenotype that defines a distinct subgroup of glioma. Cancer Cell. 2010; 17:510-522. [PubMed: 20399149]

94. Delhommeau F, Dupont S, Della Valle V, James C, Trannoy S, Masse A, et al. Mutation in TET2 in myeloid cancers. The New England journal of medicine. 2009; 360:2289-2301. [PubMed: 19474426] 
95. Langemeijer SM, Kuiper RP, Berends M, Knops R, Aslanyan MG, Massop M, et al. Acquired mutations in TET2 are common in myelodysplastic syndromes. Nature genetics. 2009; 41:838842. [PubMed: 19483684]

96. Christensen BC, Smith AA, Zheng S, Koestler DC, Houseman EA, Marsit CJ, et al. DNA methylation, isocitrate dehydrogenase mutation, and survival in glioma. J Natl Cancer Inst. 2011; 103:143-153. [PubMed: 21163902]

97. Smith EH, Janknecht R, Maher LJ 3rd. Succinate inhibition of alpha-ketoglutarate-dependent enzymes in a yeast model of paraganglioma. Human molecular genetics. 2007; 16:3136-3148. [PubMed: 17884808]

98. Adam J, Hatipoglu E, O'Flaherty L, Ternette N, Sahgal N, Lockstone H, et al. Renal Cyst Formation in Fh1-Deficient Mice Is Independent of the Hif/Phd Pathway: Roles for Fumarate in KEAP1 Succination and Nrf2 Signaling. Cancer Cell. 2011; 20:524-537. [PubMed: 22014577]

99. Bardella C, El-Bahrawy M, Frizzell N, Adam J, Ternette N, Hatipoglu E, et al. Aberrant succination of proteins in fumarate hydratase-deficient mice and HLRCC patients is a robust biomarker of mutation status. J Pathol. 2011; 225:4-11. [PubMed: 21630274]

100. Alderson NL, Wang Y, Blatnik M, Frizzell N, Walla MD, Lyons TJ, et al. S-(2Succinyl)cysteine: a novel chemical modification of tissue proteins by a Krebs cycle intermediate. Arch Biochem Biophys. 2006; 450:1-8. [PubMed: 16624247]

101. Ooi A, Wong JC, Petillo D, Roossien D, Perrier-Trudova V, Whitten D, et al. An Antioxidant Response Phenotype Shared between Hereditary and Sporadic Type 2 Papillary Renal Cell Carcinoma. Cancer Cell. 2011; 20:511-523. [PubMed: 22014576]

102. Jia G, Fu Y, Zhao X, Dai Q, Zheng G, Yang Y, et al. N6-Methyladenosine in nuclear RNA is a major substrate of the obesity-associated FTO. Nat Chem Biol. 2011; 7:885-887. [PubMed: 22002720] 
A
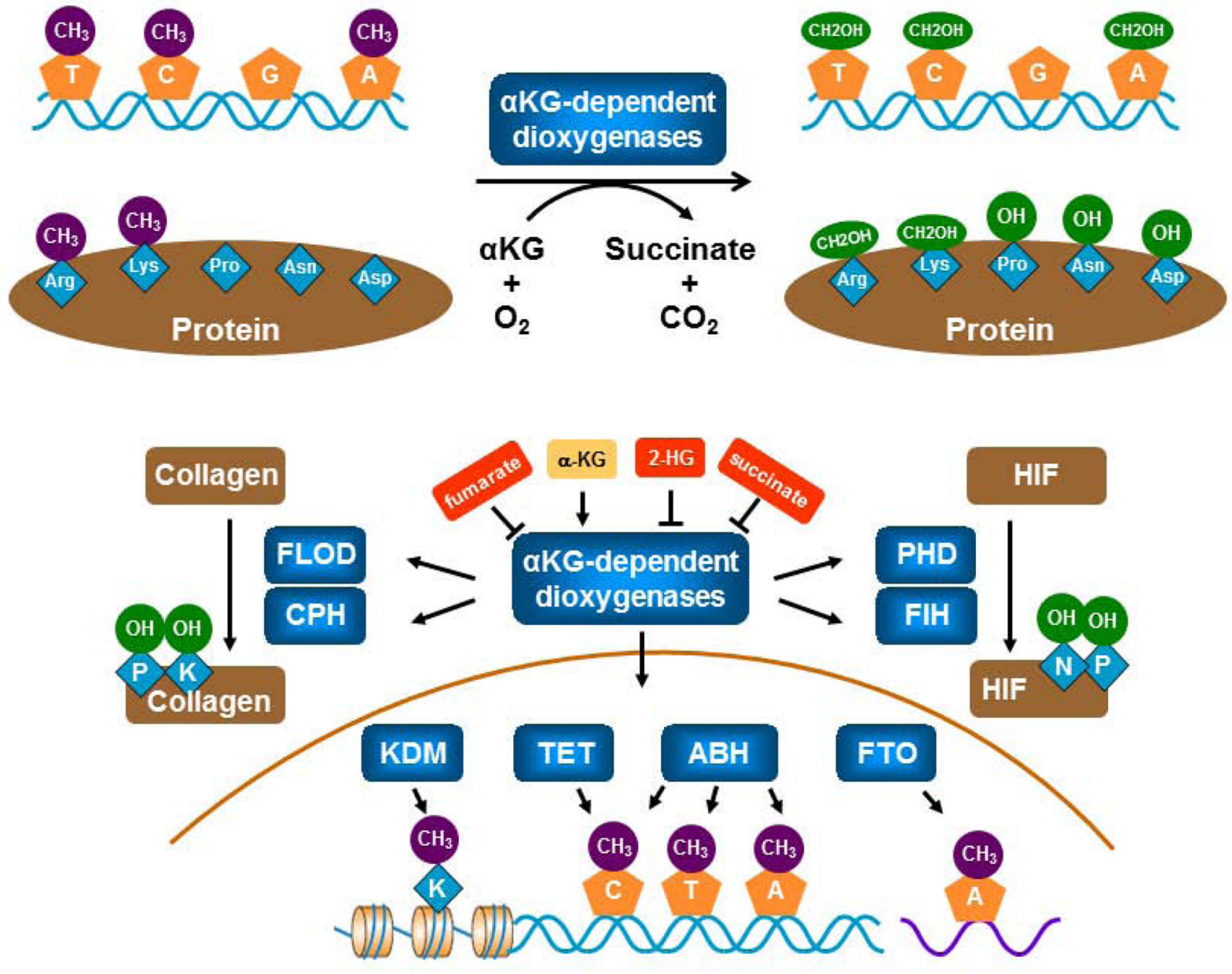

Figure 1. The substrates and regulation by metabolites of a-KG dependent dioxygenases (A) A schematic diagram of hydroxylation reaction catalyzed by the a-KG dependent dioxygenases. The substrates of this family of enzymes include both nucleic acids and proteins. Five different amino acid residues, Proline (Pro), methyllysine (Lys), methylargnine (Arg), Asparagine (Asn) and Aspartate (Asp), have been found to date to be hydroxylated. Hydroxylation of both Arg and Lys occur only on the methylated, but not unmodified residues. Four bases in DNA or RNA can be methylated by either enzyme (DNA methyltransferase)-catalyzed methylation at C-3 position of cytosine (3-meC) or alkylating agents on a variety positions of different bases. Hydroxylation of methylguanine has been reported for bacterial AlkB, but not for human AlkB homologues $(A B H)$.

(B) The currently known oncometabolites (2-HG, succinate, fumarate) act upon a wide range of $\mathrm{a}-\mathrm{KG}$ dependent dioxygenases both in the cytosol and in the nucleus. In addition to the hydroxylation of protein and DNA substrates, a member of a-KG dependent dioxygenases, fat mass and obesity (FTO) protein, can recognize and hydroxylate N6methyadenosine in nuclear RNA [102]. 
Table 1

The regulation of metabolic enzymes by classical cancer genes.

\begin{tabular}{|c|c|c|c|}
\hline Gene & Target Metabolic Enzyme & Mechanism & Metabolic Function \\
\hline \multirow[t]{3}{*}{ p53 } & $\begin{array}{l}\text { TP53-induced glycolysis and apoptosis regulator } \\
\text { (TIGAR) }\end{array}$ & Transcription & ROS-induced apoptosis protection \\
\hline & Type II hexokinase (HK2) & Transcription & First committed step of glycolysis \\
\hline & Glutaminase 2 (GLS2) & Transcription & Reaction: Glutamine $+\mathrm{H} 2 \mathrm{O} \rightarrow$ Glutamate $+\mathrm{NH} 3$ \\
\hline \multirow[t]{3}{*}{ Myc } & Lactate dehydrogenase A (LDH-A) & Transcription & Reaction: Pyruvate + NADH $\rightarrow$ Lactate + NAD+ \\
\hline & $\mathrm{miR}-23 \mathrm{a} / \mathrm{b}$ & Transcription & Glutaminase 1 (GLS1) expression \\
\hline & $\begin{array}{l}\text { Heterogenous nuclear ribonucleoprotein A1/2/I } \\
\text { (hRNPA1/2/I) }\end{array}$ & Transcription & Regulate alternative splicing of PKM2 \\
\hline \multirow[t]{6}{*}{ AMPK } & Acetyl-CoA carboxylase (ACC) & Phosphorylation & Rate limiting enzyme in fatty acid synthesis \\
\hline & HMG-CoA reductase (HMGR) & Phosphorylation & Rate limiting enzyme in cholesterol synthesis \\
\hline & Phosphofructokinase-2 (PFK2) & Phosphorylation & $\begin{array}{l}\text { Regulates PFK1 activity to balance glycolysis and } \\
\text { gluconeogenesis }\end{array}$ \\
\hline & Malonyl-CoA decarboxylase & Phosphorylation & Fatty acid biosynthesis \\
\hline & Glycogen synthase (GS) & Phosphorylation & Converts glucose into glycogen \\
\hline & Hormone sensitive lipase (HSL) & Phosphorylation & $\begin{array}{l}\text { Mobilizes free fatty acids in adipose tissue, and free } \\
\text { cholesterol in endocrine tissue. }\end{array}$ \\
\hline \multirow[t]{4}{*}{ Akt } & Glycogen synthase kinase 3 (GSK3) & Phosphorylation & $\begin{array}{l}\text { SREBP expression and fatty acid biosynthesis regulation. } \\
\text { Regulates GS. }\end{array}$ \\
\hline & $\begin{array}{l}\text { TBC1 domain family member } 4 \text { (TBC1D4/ } \\
\text { AS160) }\end{array}$ & Phosphorylation & GLUT4 cell membrane translocation \\
\hline & Type II hexokinase (HK2) & Phosphorylation & First committed step of glycolysis \\
\hline & Phosphofructokinase-2 (PFK2) & Phosphorylation & $\begin{array}{l}\text { Regulates PFK1 activity to balance glycolysis and } \\
\text { gluconeogenesis }\end{array}$ \\
\hline mTOR & Ribosomal protein S6 kinase beta-1 (S6K1) & Phosphorylation & Increased protein biosynthesis \\
\hline KRAS & ?Glucose transporter 1 (GLUT-1)? & $? ?$ & Basal glucose transport across cell membranes \\
\hline BRAF & ?Glucose transporter 1 (GLUT-1)? & $? ?$ & Basal glucose transport across cell membranes \\
\hline
\end{tabular}


Table 2

Mutation of 8 metabolic genes in human tumors

\begin{tabular}{|c|c|c|c|c|}
\hline $\begin{array}{l}\text { Enzyme and } \\
\text { Subcellular } \\
\text { Location }\end{array}$ & $\begin{array}{l}\text { Gene } \\
\text { (Chromosomal } \\
\text { Location) }\end{array}$ & Reaction catalyzed & $\begin{array}{l}\text { Somatic Tumor Types } \\
\text { or Tumor Syndromes } 1\end{array}$ & Mutation Frequency $^{2}$ \\
\hline IDH1 & $I D H 1(2 \mathrm{q} 33.3)$ & Isocitrate $+\mathrm{NADP}^{+} \rightarrow$ & Glioma $^{3}$ & Somatic, $\sim 75 \%$ \\
\hline Isocitrate & & $a-K G+N A D P H+\mathrm{CO}_{2}$ & Cartilaginous Tumors 4 & Somatic, $\sim 75 \%$ \\
\hline Dehydrogenase 1 & & & $\mathrm{AML}^{5}$ & Somatic, $\sim 20 \%$ \\
\hline Cytoplasm & & & Thyroid Carcinoma ${ }^{6}$ & Somatic, $16 \%$ \\
\hline \multirow[t]{2}{*}{ Peroxisome } & & & Melanoma & Somatic, $4 / 39$ \\
\hline & & & Prostate Carcinoma & Somatic, $2 / 75$ \\
\hline IDH2 & $I D H 2(15 q 26.1)$ & Isocitrate $+\mathrm{NADP}^{+} \rightarrow$ & Paraganglioma & Somatic, 1/131 \\
\hline Isocitrate & & $a-K G+\mathrm{NADPH}+\mathrm{CO}_{2}$ & Cholangiocarcinoma 11 & Somatic, $23 \%$ \\
\hline Dehydrogenase 2 & & & Colorectal Carcinoma & Somatic, $2 / 180$ \\
\hline Mitochondria & & & T-cell lymphoma 12 & Somatic, $45 \%$ \\
\hline FH & $F H(1 \mathrm{q} 42.1)$ & Fumarate $+\mathrm{H}_{2} \mathrm{O} \rightarrow$ & $\mathrm{HLRCC}^{7}$ & Germline: Autosomal Dominant \\
\hline Fumarate Hydratase & & s-Malate & $\mathrm{MCUL}^{8}$ & Germline: Autosomal Dominant \\
\hline Mitochondria & & & Renal Cell Carcinoma & Somatic, $1 / 3$ \\
\hline \multirow[t]{5}{*}{ Cytoplasm } & & & Melanoma & Somatic, $1 / 14$ \\
\hline & & & Leydig cell tumor & $\begin{array}{l}\text { Germline Mutation+Somatic LOH, } \\
2 / 29\end{array}$ \\
\hline & & & Ovarian Cystadenoma 9 & Germline, 2/33 \\
\hline & & & Leiomyoma & LOH + Somatic Mutation, $1.3 \%$ \\
\hline & & & Lung Adenocarcinoma & Somatic, $1.1 \%$ \\
\hline SDH & SDHA (5p15.33) & Succinate + Ubiquinone $\rightarrow$ & Familial Paraganglioma & Germline: Autosomal Dominant \\
\hline Succinate & $S D H B(1 \mathrm{p} 36.1)$ & Fumarate + Ubiquinol & Merkel Cell Carcinoma & Somatic, $2 / 7$ \\
\hline Dehydrogenase & $S D H C(1 \mathrm{q} 23.3)$ & & Paraganglioma & $\mathrm{LOH}+$ Germline, $6 / 36$ \\
\hline \multirow[t]{3}{*}{ Mitochondria } & $S D H D(11 \mathrm{q} 23.1)$ & & Midgut Carcinoid & $\mathrm{LOH}+$ Somatic, $2 / 18$ \\
\hline & $S D H A F 2(11 \mathrm{q} 12.2)$ & & $\operatorname{GIST}^{10}$ & Germline, 3/34 \\
\hline & & & Pheochromocytoma & Germline, $4.4 \%$ \\
\hline \multicolumn{5}{|c|}{${ }^{1} \mathrm{IDH} 1$ and $\mathrm{IDH} 2$ mutations are grouped together due to their mechanistic similarity and exclusive occurrence in the tumors } \\
\hline \multicolumn{5}{|c|}{2 For studies with sample number less than 100 , the actual numbers, instead of percentages of mutation are given. } \\
\hline \multicolumn{5}{|c|}{3 Glioma includes all WHOI-IV glioma. } \\
\hline \multicolumn{5}{|c|}{$\begin{array}{l}4 \text { Includes central enchondromas and chondrosarcomas, periosteal chondromas, and cartilaginous tumors associated with Maffuci and Ollier } \\
\text { syndrome. }\end{array}$} \\
\hline \multicolumn{5}{|c|}{5 AML, Acute Myelogenous Leukemia. } \\
\hline${ }^{6}$ All histological subty! & & & & \\
\hline
\end{tabular}


8 MCUL, Multiple Cutaneous and Uterine Leiomyoma.

${ }^{9}$ Mucinous histological subtype.

${ }^{10}$ GIST, Gastrointestinal Stromal Tumor.

11 Intrahepatic cholangiocarcinoma only, no mutations were found in extrahepatic cholangiocarcinoma.

12 Angioimmunoblastic T-cell lymphoma confirmed by molecular signature (w/o confirmation rate was $20 \%$ ). no mutations were found in other peripheral T-cell lymphomas. 